\title{
The self-assembly over nano- to submicro- length scales in water of a fluorescent julolidine-labeled amphiphilic random terpolymer
}

\author{
Elisa Guazzelli ${ }^{a}$, Elena Masotti $^{a}$, Tarita Biver $^{a}$, Andrea Pucci $^{a, b}$, Elisa Martinelli $^{a, b}{ }^{*}$ \\ Giancarlo Galli ${ }^{a, b}$
}

Dipartimento di Chimica e Chimica Industriale, Università di Pisa, Via G. Moruzzi 13, 56124 Pisa, Italy

INSTM, UdR Pisa, Via G. Moruzzi 13, 56124 Pisa, Italy

Correspondence to: Elisa Martinelli (E-mail: elisa.martinelli@unipi.it)

(Additional Supporting Information may be found in the online version of this article.)

\begin{abstract}
A novel fluorescent-labeled amphiphilic random terpolymer is synthesized by controlled radical polymerization of a fluorescent molecular rotor monomer, 2-cyano-2-[4-vinyl(1,1'biphenyl)-4'-yl]vinyljulolidine, a hydrophilic monomer, poly(ethylene glycol) methyl ether methacrylate, and a hydrophobic monomer, perfluorohexylethyl acrylate. Combined dynamic light scattering and fluorescence emission spectroscopy measurements are used to investigate its self-assembly in water solution. Self-assembled nanostructures with a hydrodynamic diameter size $D_{\mathrm{h}}$ of $4 \pm 1 \mathrm{~nm}$ are detected due to the single-chain folding of the terpolymer in unimer micelles. The fluorescence emission intensity of the terpolymer in water solution is found to be one order of magnitude higher than that in organic solvents, as a result of the preferential encapsulation of the julolidine co-units in hydrophobic compartments of the unimer micelles. The temperature dependence of the self-associative behavior of the amphiphilic terpolymer is also investigated and a critical temperature is identified at which a transition between single-chain unimer micelles and multi-chain aggregates $\left(D_{\mathrm{h}}=400 \pm 40\right.$ $\mathrm{nm})$ reversibly takes place on heating-cooling cycles.
\end{abstract}

Keywords: unimer micelles, amphiphilic polymers, fluorescent molecular rotors, selfassembly, thermoresponsive polymers 


\section{INTRODUCTION}

Single-chain polymeric nanoparticles (SCNPs) are an emerging class of functional nanomaterials in which one polymer chain folds/collapses into a particle with sub-30 nm diameter. Namely, SCNPs have attracted significant attention in the nanoscience community during the last years for potential applications ranging from nanomedicine to nanocatalysis. ${ }^{[1-}$ ${ }^{5]}$ Water-compatible SCNPs, referred to as unimer micelles, ${ }^{[6]}$ are spontaneously formed in water through the intramolecular self-assembly of the hydrophobic portions of the amphiphilic random copolymers. ${ }^{[7,8]}$ Early work on unimer micelles was based on amphiphilic polyelectrolytes where hydrophilic ionic units were combined with hydrophobic units. ${ }^{[9-11]}$ More recently, non-ionic amphiphilic polymers with a well-defined primary structure (chain length, monomer sequence and hydrophilic/hydrophobic balance) were found to autonomously undergo single-chain self-folding in water solution to SCNPs consisting of hydrophobic mono- or multi-compartments. ${ }^{[12-15]}$ Poly(ethylene glycol) methyl ether methacrylate (PEGMA) was used as a preferred hydrophilic monomer. PEGMA-based polymers have, in fact, an amphiphilic nature per se and display a lower critical solution temperature (LCST)-type phase separation, which depends on the length of the oxyethylenic pendant chains. ${ }^{[16,17]}$ On the other hand, alkyl or fluoroalkyl methacrylate co-monomers were used as the hydrophobic components. The self-assembled amphiphilic SCNPs were dynamic, reversible and thermo-responsive in water. The thermo-responsiveness depended on the content of the hydrophobic component in the copolymer.

In keeping with this rationale, the present work focuses on a new amphiphilic random terpolymer in which a fluorescent molecular rotor monomer was incorporated as a fluorescent label to probe the self-assembly behavior in water solution as a function of temperature. Fluorescence emission techniques are particularly useful to explore short-dimensional structure, such as SCNPs, and several strategies have been described in the literature to endow 
SCNPs with fluorescence emission properties, including physical dispersion and covalent anchorage of a fluorophore probe ${ }^{[6,18]}$ However, while fluorescence emission studies of the self-associative behavior have been reported for ionic amphiphilic random copolymers containing covalently linked fluorophores, ${ }^{[19]}$ to the best of our knowledge, only the physical dispersion of fluorophores has been investigated for non-ionic random copolymers. ${ }^{[12]}$ Herein, the fluorescence labeling was performed by atom transfer controlled radical terpolymerization of a minimal amount of the 2-cyano-2-[4-vinyl(1,1'-biphenyl)-4'-yl]vinyljulolidine (JCBF) fluorescent molecular rotor together with the hydrophobic perfluorohexylethyl acrylate (FA) and the hydrophilic poly(ethylene glycol) methyl ether methacrylate (PEGMA).

Fluorescent molecular rotors (FMRs) belong to the class of aggregation induced emission (AIE) luminophores and are generally composed of an electron donor unit in conjugation with an electron acceptor moiety. ${ }^{[20,21]}$ In dilute solution, FMRs can adopt a non-emissive twisted intramolecular charge transfer (TICT) state, while in aggregates the TICT state is inhibited in favor of the radiative emitting locally excited (LE) state. ${ }^{[22-25]}$ Non-radiative deactivation of the LE state is controlled by rapid internal torsional motion, which is substantially restricted in viscous media. ${ }^{[26-28]}$ According to this accepted mechanism, the fluorescence emission of the amphiphilic random terpolymer was anticipated to be drastically affected by the viscosity changes in the local micro-environment embedding the julolidine label co-unit and was expected to increase when such FMR residues were constrained within an hydrophobic compartment of the terpolymer unimer micelles. Fluorescence studies combined with dynamic light scattering (DLS) analysis carried out as a function of temperature also proved the thermo-responsive behavior of the amphiphilic terpolymer and the existence of a critical temperature $\left(T_{\mathrm{c}}\right)$ at which a reversible transition between single-chain and multi-chain selfassemblies took place. Such a temperature dependent self-assembling system might be exploited in the field of nanotherapy for the development of novel controlled and targeted drug delivery systems. 


\section{EXPERIMENTAL}

\section{Materials}

Anisole (Sigma Aldrich) was vacuum distilled over sodium. CuBr (Sigma Aldrich) was extracted with glacial acetic acid and then washed with diethyl ether, dried and stored under nitrogen. $N, N, N^{\prime}, N^{\prime \prime}, N^{\prime \prime}$-Pentamethyldiethylenetriamine (PMDETA, Sigma Aldrich) and ethyl $\alpha$-bromophenylacetate (EBPA, Sigma Aldrich) were freshly distilled before use. Perfluorohexylethyl acrylate (FA, Fluoryx) and poly(ethylene glycol) methyl ether methacrylate (PEGMA, $M_{\mathrm{n}}=300 \mathrm{~g} \mathrm{~mol}^{-1}$, Sigma Aldrich) were filtered on basic alumina to remove inhibitors. Common laboratory solvents and other reagents (Sigma Aldrich) were used as received.

2-Cyano-2-[4-vinyl(1,1'-biphenyl)-4'-yl]vinyljulolidine (JCBF) was synthesized according to a reported procedure. ${ }^{[35]}$

Ethidium bromide (EtBr, purity 99\%, Sigma) solutions were prepared by dissolving weighed amounts in water and their molar concentration was verified spectrophotometrically $(\varepsilon=5600$ $\mathrm{M}^{-1} \cdot \mathrm{cm}^{-1}$ at $\left.\lambda=480 \mathrm{~nm}\right) .^{[41]}$

\section{Synthesis of terpolymer PEGMA74-co-FA25-co-JCBF1}

PEGMA (0.706 mL, $2.47 \mathrm{mmol})$, FA (0.162 mL, $0.60 \mathrm{mmol})$, JCBF (6.20 mg, $0.015 \mathrm{mmol})$, PMDETA $(6.45 \mu \mathrm{L}, 0.03 \mathrm{mmol})$, EBPA $(5.4 \mu \mathrm{L}, 0.03 \mathrm{mmol})$ and anisole $(0.5 \mathrm{~mL})$ were degassed in a Schlenck tube with three freeze-pump-thaw cycles. Then $\mathrm{CuBr}(4.4 \mathrm{mg}, 0.03$ mmol) was added and three more freeze-pump-thaw cycles were performed before the polymerization was started at $70{ }^{\circ} \mathrm{C}$ under nitrogen atmosphere. After 24 hours, the reaction was stopped by exposure to air and quenching to $0{ }^{\circ} \mathrm{C}$. The crude product was filtered on basic alumina to remove the catalyst. Final purification required repeated precipitations from chloroform solutions into $n$-hexane ( $53 \%$ yield).

$\operatorname{SEC}\left(\mathrm{CHCl}_{3}\right.$, PMMA std. $) M_{\mathrm{n}}=6900 \mathrm{~g} \mathrm{~mol}^{-1}, M_{\mathrm{w}} / M_{\mathrm{n}}=1.25$. 
${ }^{1} \mathrm{H}$ NMR (acetone-d $\left.{ }_{6}\right) \delta(\mathrm{ppm}):=4.0-4.6\left(\mathrm{COOCH}_{2}\right), 3.4-3.6\left(\mathrm{OCH}_{2} \mathrm{CH}_{2}, \mathrm{CHCOO}\right), 3.3$ $\left(\mathrm{OCH}_{3}\right), 2.5\left(\mathrm{CH}_{2} \mathrm{CF}_{2}\right), 0.7-2.3\left(\mathrm{CH}, \mathrm{CH}_{2}, \mathrm{CH}_{3}\right)$.

${ }^{19} \mathrm{~F}$ NMR (acetone- $\left.\mathrm{d}_{6} / \mathrm{CF}_{3} \mathrm{COOH}\right): \delta(\mathrm{ppm})=-5.6\left(\mathrm{CF}_{3}\right),-38.5\left(\mathrm{CF}_{2} \mathrm{CH}_{2}\right),-46$ to $-48\left(\mathrm{CF}_{2}\right)$, $-51\left(\mathrm{CF}_{2} \mathrm{CF}_{3}\right)$.

A julolidine-free PEGMA-co-FA copolymer was separately prepared in the same experimental conditions. The reaction was stopped after $24 \mathrm{~h}(82 \%$ total monomer conversion) and the crude product was filtered on basic alumina to remove catalyst and repeatedly precipitated from chloroform solutions into $n$-hexane ( $54 \%$ yield). The obtained copolymer contained 77 mol\% PEGMA.

\section{Characterization}

${ }^{1} \mathrm{H}$ NMR and ${ }^{19} \mathrm{~F}$ NMR solution spectra were recorded with a Bruker Avance DRX 400 spectrometer.

The number and weight average molecular weights of the polymers were determined by size exclusion chromatography (SEC) with a Jasco PU-2089Plus liquid chromatograph equipped with two PL gel $5 \mu$ m mixed-D columns, a Jasco RI-2031Plus refractive index detector and a Jasco UV-2077Plus UV/vis detector. Poly(methyl methacrylate) standards (1160 $\mathrm{g} \mathrm{mol}^{-1}$ $124300 \mathrm{~g} \mathrm{~mol}^{-1}$ ) were used for calibration.

Dynamic light scattering (DLS) distributions of scatters were taken with a Beckman Coulter Delsa Nano $\mathrm{C}$ particle analyzer (detection angle $=166.22^{\circ}$ ). Intensity, volume and number distributions were obtained from the signal autocorrelation function through CONTIN analysis in the instrument software. Samples were prepared in filtered solvent $(0.2 \mu \mathrm{m} \mathrm{CA}$ or PTFE filters) of the highest purity available to reduce external contamination.

Absorption spectra were recorded at room temperature on a Perkin-Elmer Lambda 650 spectrophotometer. An absorption calibration curve $\left(A=\varepsilon \cdot \operatorname{conc}\right.$, where $\varepsilon=21500 \mathrm{M}^{-1} \cdot \mathrm{cm}^{-1}$, 
light path $1 \mathrm{~cm}$ ), obtained from $5 \cdot 10^{-7}-5 \cdot 10^{-5} \mathrm{M}$ chloroform solutions of the fluorescent monomer $\left(\mathrm{R}^{2}=0.9997\right)$, allowed evaluation of the chemical composition of the terpolymer. The molar extinction coefficient variation from monomer to polymer was assumed to be negligible.

Fluorescence emission spectra were recorded on a Horiba Jobin-Yvon Fluorolog-3 spectrofluorometer equipped with a $450 \mathrm{~W}$ xenon arc lamp, double-grating excitation and single-grating emission monochromators. Fluorescence quantum yield $\Phi$ was determined using perylene in ethanol as standard, ${ }^{[42]}$ as a result of Equation 1:

$\Phi=\Phi_{s t} \frac{\int_{0}^{\infty} I_{(v)} d v}{\int_{0}^{\infty} I_{s t(v)} d v} \frac{\left(1-10^{-A s t}\right)}{\left(1-10^{-A}\right)} \frac{n^{2}}{n_{s t}^{2}}$

where $\int_{0}^{\infty} I_{(v)} d v$ is the area under the emission curve (in the $420-670 \mathrm{~nm}$ range), $A$ is the absorbance at excitation wavelength, $n$ is the refractive index, and the $s t$ subscript means the value referring to perylene standard.

For FRET experiments a Perkin Elmer LS55 spectrofluorometer was used to record fluorescence spectra.

\section{RESULTS AND DISCUSSION}

Synthesis of the fluorescent amphiphilic terpolymer

A fluorescent amphiphilic random terpolymer was synthesized by controlled radical polymerization (ATRP) of a hydrophobic perfluorohexylethyl acrylate (FA), a hydrophilic poly(ethylene glycol) methyl ether methacrylate (PEGMA, $M_{\mathrm{n}}=300 \mathrm{~g} \mathrm{~mol}^{-1}$ ) and a fluorophore 2-cyano-2-[4-vinyl(1,1'-biphenyl)-4'-yl]vinyljulolidine (JCBF) by using ethyl $\alpha$ bromophenylacetate (EBPA) as initiator, $\mathrm{CuBr}$ as catalyst, PMDETA as ligand in anisole solution $\left(0.5 \mathrm{~mL} \mathrm{~g} \mathrm{~g}^{-1}\right.$ of monomers) at $70{ }^{\circ} \mathrm{C}$. The initial molar ratio was 1:1:1 for 
EBPA:CuBr:PMDETA and 100:1 for co-monomers:EBPA (Figure 1). The chemical constitution of the terpolymer was tailored in such a design that the content of the PEGMA:FA co-units warranted solubility in water (as well as organic solvents) (ca. 75:25 mol\%:mol\%) and the content of JCBF co-units ensured UV light absorption-emission from isolated FMR labels (ca. 1 mol\%). The covalent anchorage of the fluorescent probe JCBF was necessary, given its very poor solubility in water.

The formation of the copolymer was confirmed by ${ }^{19} \mathrm{~F}$ NMR spectroscopy which proved the insertion of the fluoroalkyl co-units in the polymer structure (Figure S1). The relative PEGMA and FA content was evaluated from the integrated areas of the ${ }^{1} \mathrm{H}$ NMR characteristic signals (4.4 ppm for $\mathrm{COOCH}_{2}$ of both FA and PEGMA and $3.3 \mathrm{ppm}$ for $\mathrm{OCH}_{3}$ of PEGMA) (Figure S2). The JCBF content was determined by UV absorption measurements of terpolymer solutions in chloroform, by using a calibration curve obtained for the respective monomer solutions in chloroform $\left(5 \cdot 10^{-7}-5 \cdot 10^{-5} \mathrm{M}\right)$. The JCBF chromophore did not exhibit significant variation in its spectroscopic properties when incorporated in the amphiphilic polymer. The terpolymer was found to consist of 74,25 and 1 mol\% of PEGMA, FA and JCBF, respectively and was named PEGMA74-co-FA25-co-JCBF1. Thus, the fluorescent JCBF co-units were isolated along the polymer chain backbone.

\section{Temperature-dependent self-assembly behavior in water}

\section{DLS analysis}

DLS measurements of the amphiphilic/fluorinated terpolymer solutions in water were performed to directly monitor the ability to self-assemble in organized nanostructures. The analysis was carried out at room temperature and as a function of temperature in heatingcooling cycles. At room temperature clear solutions of PEGMA74-co-FA25-co-JCBF1 in water showed a monomodal distribution of scattering particles, with an intense peak centered at small values of hydrodynamic diameter $\left(D_{\mathrm{h}} \approx 4 \pm 1 \mathrm{~nm}\right)$ (Figure 3a), consistent with the 
formation of single-chain folded macromolecules ${ }^{[29]}$ (Figure 2). Similar PEGMA-co-FA copolymers were recently shown to self-fold in compact unimer micelles in water solutions, consisting of a fluorous core and a hydrophilic PEG shell, with dimensions in the range $D_{\mathrm{h}}=$ 11-22 nm. ${ }^{[13]}$ The smaller scattering particles persisted unchanged up to a critical temperature $\left(T_{\mathrm{c}}=55^{\circ} \mathrm{C}\right)$, above which they collapsed into larger multi-chain aggregates with $D_{\mathrm{h}}=400 \pm$ $40 \mathrm{~nm}$ and a very narrow size distribution, via self-association of unimer micelles (Figure 3b). Moreover, this phenomenon was reversible in successive heating-cooling cycles with almost no temperature hysteresis (Figure 3c).

These two different self-association states could be easily distinguished by naked eyes, being the solutions perfectly homogeneous and transparent at room temperature, while they turned to cloudy at $T \geq T_{\mathrm{c}}$, because of the formation of larger submicro-aggregates (insets of Figure 4). The value of a cloud point $(\mathrm{Cp})$, identified as the temperature at which the transmittance at $\lambda=700 \mathrm{~nm}$ dropped from $100 \%$ to $50 \%$, was determined by temperature-dependent UV-vis measurements of terpolymer aqueous solutions. In agreement with the $T_{\mathrm{c}}$ value from DLS, the $\mathrm{Cp}$ was $53{ }^{\circ} \mathrm{C}$ at which a sharp and reversible LCST-type phase separation occurred without any temperature hysteresis (Figure 4). PEGMA homopolymers containing $\left(\mathrm{OCH}_{2} \mathrm{CH}_{2}\right)_{\mathrm{n}} \mathrm{OCH}_{3}$ side chain segments with $2 \leq n \leq 8.5$ show a LCST behavior in water, with a critical temperature strictly depending on the length of the oxyethylene side chain. ${ }^{[16]}$ Being PEGMA homopolymers amphiphilic in nature, the hydrophilic oxyethylene units of the side chains tend to form hydrogen bonds with the surrounding molecules of water, while the apolar methacrylic backbone is involved in hydrophobic interactions. Above $T_{\mathrm{c}}$, the hydrogen bonds break down and the hydrophobic interactions become predominant. ${ }^{[16]}$ A similar mechanism also triggers the thermo-responsiveness of the present fluorescent amphiphilic terpolymer. However, the more marked hydrophobic nature of the FA co-units of the latter leads to a lower $T_{\mathrm{c}}$ than that reported for the corresponding homopolymer $\left(\sim 66^{\circ} \mathrm{C}\right) \cdot{ }^{[17]}$ The inclusion of low surface energy fluoroalkyl side chains in a polymer structure is, in fact, known to 
drastically enhance the hydrophobic and lipophobic nature of the entire system which results in a strong capability to self-assemble in solution, in bulk and at the surface of thin films. ${ }^{[30-34]}$

\section{Fluorescence emission spectroscopy}

By taking advantage of the covalent anchorage of the fluorescent JCBF co-unit within the terpolymer backbone, its self-associative behavior in water was studied as a function of temperature by monitoring the fluorescence response of the JCBF probe. An in-depth characterization of the JCBF monomer was recently published. ${ }^{[35]}$ Briefly, UV-vis spectra of $\mathrm{JCBF}$ in chloroform solutions showed a characteristic absorption peak at around $407 \mathrm{~nm}(\varepsilon=$ $21500 \mathrm{M}^{-1} \cdot \mathrm{cm}^{-1}$ ), typical of cyanovinyl julolidine derivatives, ${ }^{[36,37]}$ and a second absorption peak at about $290 \mathrm{~nm}$, due to the $\pi \rightarrow \pi^{*}$ electronic transition of the biphenyl moiety. The fluorescence emission maximum was at around $500 \mathrm{~nm}\left(\lambda_{\mathrm{exc}}=410 \mathrm{~nm}\right)$ with a negligible fluorescence quantum yield $\left(\Phi=2.11 \cdot 10^{-3}\right)$ due to the preferential formation, in low viscosity media, of the radiationless TICT excited state. As expected of FMR, JCBF underwent a strong increase in quantum yield (about 30x) when dissolved in viscous environments, such as glycerol-containing solutions (viscosity $\eta=630 \mathrm{mPa} \cdot \mathrm{s}$ at $20{ }^{\circ} \mathrm{C}$ for a methanol/glycerol 10:90 $\mathrm{v} / \mathrm{v}$ mixture, as compared to $0.6 \mathrm{mPa} \cdot \mathrm{s}$ for pure methanol).${ }^{[35]}$ In fact, according to the FMR behavior the molecular internal rotation of the molecule is hampered in viscous media, thus promoting the emission from the LE and, in turn, increasing the quantum yield. Consistent with the optical properties of the monomer JCBF, terpolymer in chloroform solutions showed absorption and emission maxima at $405 \mathrm{~nm}$ and $500 \mathrm{~nm}\left(\lambda_{\mathrm{exc}}=405 \mathrm{~nm}\right)$ (Figure 5 and Figure S3), with an associated negligible quantum yield $\left(\Phi=5.11 \cdot 10^{-3}\right)$. This value was slightly higher than that of the corresponding monomer, owing to the enhanced steric hindrance of the JCBF moiety covalently linked to the macromolecular chain. ${ }^{[37]}$

In Figure 6 the terpolymer fluorescence emission spectra in water, chloroform and hexafluorobenzene (HFB) solutions are compared. Being the single-chain folding driven by 
the intramolecular self-assembly of the different macromolecular components on the basis of their specific affinity and interactions with the solvent of choice, a solvent-dependent specific response of the fluorescent probe was expected. Interestingly, the maximum fluorescence emission intensity (443600 cps) of the terpolymer solutions in water and the respective quantum yield $\left(\Phi=4.44 \cdot 10^{-2}\right)$ were almost one order of magnitude higher than those collected in chloroform (4400 cps and $\left.\Phi=5.11 \cdot 10^{-3}\right)$. This result confirmed the formation in water of single-chain folded unimer micelles in order to maximize the mutual interactions among the hydrophobic FA chains within a hidden core to water. On the other hand, such nanostructure enabled the hydrophilic PEGMA chains within an outer shell to maximize contact with water. Moreover, the hydrophobic JCBF co-units were preferentially located into the hydrophobic compartments, which caused a reduction in their degree of mobility, thus resulting in an increased intensity of fluorescence emission. Similar to chloroform, hexafluorobenzene was found to be a relatively good solvent for both FA and PEGMA components of the terpolymer, as the fluorescence emission intensity and quantum yield of these solutions were more than five times lower than in water. This was in agreement with the presence of polymer chains adopting a more loosely open conformation. The increased quantum yield $\left(\Phi=8.11 \cdot 10^{-3}\right)$ in hexafluorobenzene with respect to chloroform $\left(\Phi=5.11 \cdot 10^{-}\right.$ $\left.{ }^{3}\right)$ solutions was associated with the higher viscosity $(1.2 \mathrm{mPa} \cdot \mathrm{s})$ of the former solvent relative to the latter $(0.5 \mathrm{mPa} \cdot \mathrm{s})$. Consistently, DLS measurements in chloroform solutions, did not reveal the presence of self-assembled species.

The influence of temperature on the fluorescence emission of the amphiphilic terpolymer in water was also assessed on heating-cooling cycles in the range $25-65{ }^{\circ} \mathrm{C}$. Fluorescence emission decreased in intensity with increasing temperature (Figure 7a). As expected, the solution viscosity decreased and collisional quenching increased, thus resulting in a decreasing fluorescence emission with a linear trend (Figure 7b). However, such a trend underwent a sharp variation in slope at a critical temperature of $55^{\circ} \mathrm{C}$ (Figure 7b), which 
well agreed with the value of $T_{\mathrm{c}}$ found by both temperature-dependent DLS and UV-vis measurements (Figures 3c and $\mathbf{4}$, respectively), associated with the transition from unimer micelles to multi-chain aggregates. The marked reduction in the slope of the linear trend of fluorescence emission above the $T_{\mathrm{c}}$ reflected a lower sensitivity of the terpolymer to further increments in temperature. The inclusion of the hydrophobic fluorescent probe in stable submicro-sized multi-chain aggregates led to a great decrease in JCBF mobility which sustained the fluorescence response with increasing temperature. Fluorescence emission was completely recovered at the same $T_{c}$ by cooling down from 65 to $35^{\circ} \mathrm{C}$ on repeated heatingcooling cycles (Figure 7a), confirming that the temperature-dependent transition from unimer micelles to multi-chain aggregates was reversible.

\section{PEGMA74-co-FA25-co-JCBF1/EtBr energy transfer}

Ethidium bromide (EtBr) is a chromophore widely used as a fluorescent probe in molecular biology, thanks to its ability of tightly intercalate into DNA with subsequent enhancement in fluorescence emission. In fact, although $\mathrm{EtBr}$ is weakly fluorescent in water, its intensity increases very significantly upon binding to the hydrophobic and restricted core of a nucleic acid. ${ }^{[38,39]}$ Despite the positive charge borne by the ethidium moiety, its strong affinity for DNA points out its hydrophobicity, owing to the extended aromatic core of the molecule. Therefore, it was expected that EtBr could establish hydrophobic interactions with the unimer micelles containing the JCBF molecular rotor of PEGMA74-co-FA25-co-JCBF1 in water solution. Given the large spectral overlap between the emission spectrum $\left(\lambda_{\mathrm{exc}}=405 \mathrm{~nm}\right)$ of the terpolymer and the absorption spectrum of EtBr (Figure S4), PEGMA74-co-FA25-coJCBF1 and EtBr may act as a fluorescence resonance energy transfer (FRET) donor-acceptor pair, provided they come closer than the Förster radius. ${ }^{[38,40]}$ Figure 8 shows the emission $\operatorname{spectra}\left(\lambda_{\text {exc }}=405 \mathrm{~nm}\right)$ for PEGMA74-co-FA25-co-JCBF1 alone $\left(7.99 \cdot 10^{-5} \mathrm{M}\right)$, EtBr alone $\left(7.08 \cdot 10^{-5} \mathrm{M}\right)$ and for a mixture of both $\left(7.99 \cdot 10^{-5} \mathrm{M} \mathrm{JCBF}+7.08 \cdot 10^{-5} \mathrm{M} \mathrm{EtBr}\right)$. The marked 
decrease in the fluorescence emission intensity of JCBF ( $>40 \%$ loss) recorded for the mixture solution with respect to the terpolymer solution was attributed to a the FRET between the JCBF donor-EtBr acceptor in a close proximity of each other ${ }^{[38,40]}$ Such dramatic loss in fluorescence intensity was in fact much larger than any possible inner filter effect due to the presence of $\operatorname{EtBr}\left(\varepsilon_{\mathrm{EtBr}}\right.$ at $\left.405 \mathrm{~nm}=\mathrm{ca} .900 \mathrm{M}^{-1} \cdot \mathrm{cm}^{-1}\right)$. The observation of the FRET phenomenon suggests that the distance between the JCBF in the terpolymer and the EtBr was within a distance range of 1.5-6.0 $\mathrm{nm}$. Note that, however, no parallel increase in the emission band intensity of EtBr at $610 \mathrm{~nm}$ occurred. Therefore, despite the proximity to the unimer micelle, EtBr was yet not sheltered enough from surrounding water molecules or blocked enough in its mobility so that its emission could lighten up. Such a finding suggests a picture for the nanostructure of these unimer micelles where the inner compartment has a degree of flexibility. Structurally related PEGMA-co-FA random copolymers were previously reported to self-fold in unimer micelles with nanosized spherical shape and core-shell morphology with a compact hydrophobic/fluorous compartment in water solution. ${ }^{[13,14]}$ This conformational aspect needs to be better elucidated and will be the object of our further studies.

\section{CONCLUSIONS}

A novel fluorescent-labeled amphiphilic terpolymer was synthesized by ATRP in which a deliberately small amount of a julolidine-based FMR monomer was incorporated to impart an aggregation-dependent fluorescence response. The terpolymer formed unimer micelles by single-chain folding in water, their formation being driven by the intramolecular hydrophobic interactions of the perfluorinated pendant chains. Owing to hydrophobic compartmentalization, the julolidine chromophore was preferentially embedded in the unimer micelles and exhibited variable fluorescence emission intensity and quantum yield. Moreover, 
the julolidine-labeled micelle could possibly act as a FRET donor when the ethidium bromide acceptor was also added to water solution.

A thermo-responsive behavior of the amphiphilic terpolymer in water was also pointed out by temperature-dependent DLS, UV-vis and fluorescence spectroscopy measurements by which a transition from single-chain, intramolecular assemblies to multi-chain, intermolecular assemblies reversibly occurred at a critical temperature with an associated cloud point.

The versatility of the design and synthesis combined with the capability to stimulate the selfassembly behavior from nano- to sub-microsized aggregates as a function of temperature makes such amphiphilic random terpolymers potentially effective for advanced applications, in e.g. controlled and targeted drug delivery systems where additionally tracking and imaging of chemically incorporated labels are feasible.

\section{ACKNOWLEDGEMENTS}

Work performed with partial financial support from the University of Pisa (fondi Progetti di Ricerca di Ateneo, PRA_2017_28).

\section{REFERENCES}

[1] M. Ouchi, N. Badi, J.-F. Lutz, M. Sawamoto, Nat. Chem. 2011, 3, 917.

[2] A. Sanchez-Sanchez, J. A. Pomposo, Part. Part. Syst. Charact. 2014, 31, 11.

[3] (a) O. Altintas, C. Barner-Kowollik, Macromol. Rapid Commun. 2015, 37, 29; (b) O. Altintas, C. Barner-Kowollik, Macromol. Rapid Commun. 2012, 33, 958.

[4] T. Terashima, T. Mes, T. F. A. De Greef, M. A. J. Gillissen, P. Besenius, A. R. A. Palmans E. W. Meijer, J. Am. Chem. Soc. 2011, 133, 4742.

[5] A. M. Hanlon, C. K. Lyon, E. B. Berda, Macromolecules 2016, 49, 2.

[6] T. Terashima, M. Sawamoto, in Single-Chain Polymer Nanoparticles: Synthesis, Characterization, Simulations and Applications, (Eds: J. A. Pomposo), Wiley-VCH, Weinheim, Germany, 2017, Ch. 8.

[7] L. Li, K. Raghupathi, C. Song, P. Prasad, S. Thayumanavan, Chem. Commun. 2014, $50,13417$. 
[8] G. M. ter Huurne, L. N. J. de Windt, Y. Liu, E. W. Meijer, I. K. Voets, A. R. A. Palmans, Macromolecules 2017, 50, 8562.

[9] Y. Morishima, S. Nomura, T. Ikeda, M. Seki, M. Kamachi, Macromolecules 1995, 28, 2874.

[10] Y. Morishima, in Functional Monomers and Polymers, $2^{\text {nd }}$ edition, (Eds: K. Takemoto, R. M. Ottenbrite, M. Kamachi), Marcel Dekker Inc., New York, USA, 1997, Ch. 13.

[11] H. Yamamoto, M. Mizusaki, K. Yoda, Y. Morishima, Macromolecules 1998, 31, 3588 .

[12] T. Terashima, T. Sugita, K. Fukae, M. Sawamoto, Macromolecules 2014, 47, 589.

[13] Y. Koda, T. Terashima, M. Sawamoto, Macromolecules 2016, 49, 4534.

[14] Y. Koda, T. Terashima, M. Sawamoto, H. D. Maynard, Polym. Chem. 2015, 6, 240.

[15] M. Matsumoto, T. Terashima, K. Matsumoto, M. Takenaka, M. Sawamoto, J. Am. Chem. Soc. 2017, 139, 7164.

[16] J.-F. Lutz, J. Polym. Sci. A Polym. Chem. 2008, 46, 3459.

[17] D. Szweda, R. Szweda, A. Dworak, B. Trzebicka, Polimery 2017, 62, 298.

[18] J. De-La-Cuesta, E. Gonzalez, J. A. Pomposo, Molecules 2017, 22, 1819.

[19] S. Yusa, A. Sakakibara, T. Yamamoto, Y. Morishima, Macromolecules 2002, 35, 10182.

[20] J. Mei, N. L. C. Leung, R. T. K. Kwok, J. W. Y. Lam, B. Z. Tang, Chem. Rev. 2015, 115,11718 .

[21] G. Feng, R. T. K. Kwok, B. Z. Tang, B. Liu, Appl. Phys. Rev. 2017, 4, 021307.

[22] M. A. Haidekker, M. Nipper, A. Mustafic, D. Lichlyter, M. Dakanali, E. A. Theodorakis, in Advanced Fluorescence Reporters in Chemistry and Biology I: Fundamentals and Molecular Design, (Eds: A.P. Demchenko), Springer, Berlin, Germany, 2010, Ch. 8.

[23] F. Zhou, J. Shao, Y. Yang, J. Zhao, H. Guo, X. Li, S. Ji, Z. Zhang, Eur. J. Org. Chem. 2011, 25, 4773 .

[24] N. Amdursky, Y. Erez, D. Huppert. Acc. Chem. Res. 2012, 451548.

[25] B. Valeur, M. N. Berberan-Santos, Molecular Fluorescence: Principles and Applications, $2^{\text {nd }}$ edition, Wiley-VCH, Weinheim, Germany, 2012.

[26] L.-L. Zhu, D.-H. Qu, D. Zhang, Z.-F. Chen, Q-C Wang, H. Tian, Tetrahedron 2010, $66,1254$.

[27] L. L. Zhu, X. Li, F.-Y. Ji, X. Ma, Q.-C. Wang, Tian H. Langmuir 2009, 25, 3482. 
[28] Y.-J. Jin, H. Park, Y.-J. Ohk, G. Kwak, Polymer 2017, 132, 79.

[29] J. A. Pomposo, I. Perez-Baena, F. Lo Verso, A. J. Moreno, A. Arbe, J. Colmenero, ACS Macro Lett. 2014, 3, 767.

[30] E. Martinelli, I. Del Moro, G. Galli, M. Barbaglia, C. Bibbiani, E. Mennillo, M. Oliva, C. Pretti, D. Antonioli, M. Laus, ACS Appl. Mater. Interfaces 2015, 7, 8293.

[31] Y. Y. Durmaz, E. L. Sahkulubey, Y. Yagci, E. Martinelli, G. Galli, J. Polym. Sci. Part A: Polym. Chem., 2012, 50, 4911.

[32] E. Martinelli, G. Galli, S. Krishnan, M. Y. Paik, C. K. Ober, D. A. Fischer, J. Mater. Chem. 2011, 21, 15357.

[33] E. Martinelli, D. Gunes, B. M. Wenning, C. K. Ober, J. A. Finlay, M. E. Callow, J. A. Callow, A. Di Fino, A. S. Clare, G. Galli, Biofouling 2016, 32, 81.

[34] E. Martinelli, A. Glisenti, B. Gallot, G. Galli, Macromol. Chem. Phys. 2009, 210, 1746.

[35] M. Borelli, G. Iasilli, P. Minei, A. Pucci, Molecules 2017, 22, 1306.

[36] G. Martini, E. Martinelli, G. Ruggeri, G. Galli, A. Pucci, Dyes Pigm. 2015, 113, 47.

[37] G. Iasilli, F. Martini, P. Minei, G. Ruggeri, A. Pucci, Faraday Discuss. 2017, 196, 113.

[38] J. R. Lakowicz, Principles of Fluorescence Spectroscopy, $3^{\text {rd }}$ edition, Springer, New York, USA 2006.

[39] G. Weber, Biochemistry 1973, 12, 4161.

[40] D. Banerjee, S. K. Pal, J. Phys. Chem. B, 2007, 111, 5047.

[41] M. J. Waring, J.Mol. Biol. 1965, 13, 269.

[42] A. M. Brouwer, Pure Appl. Chem. 2011, 83, 2213. 


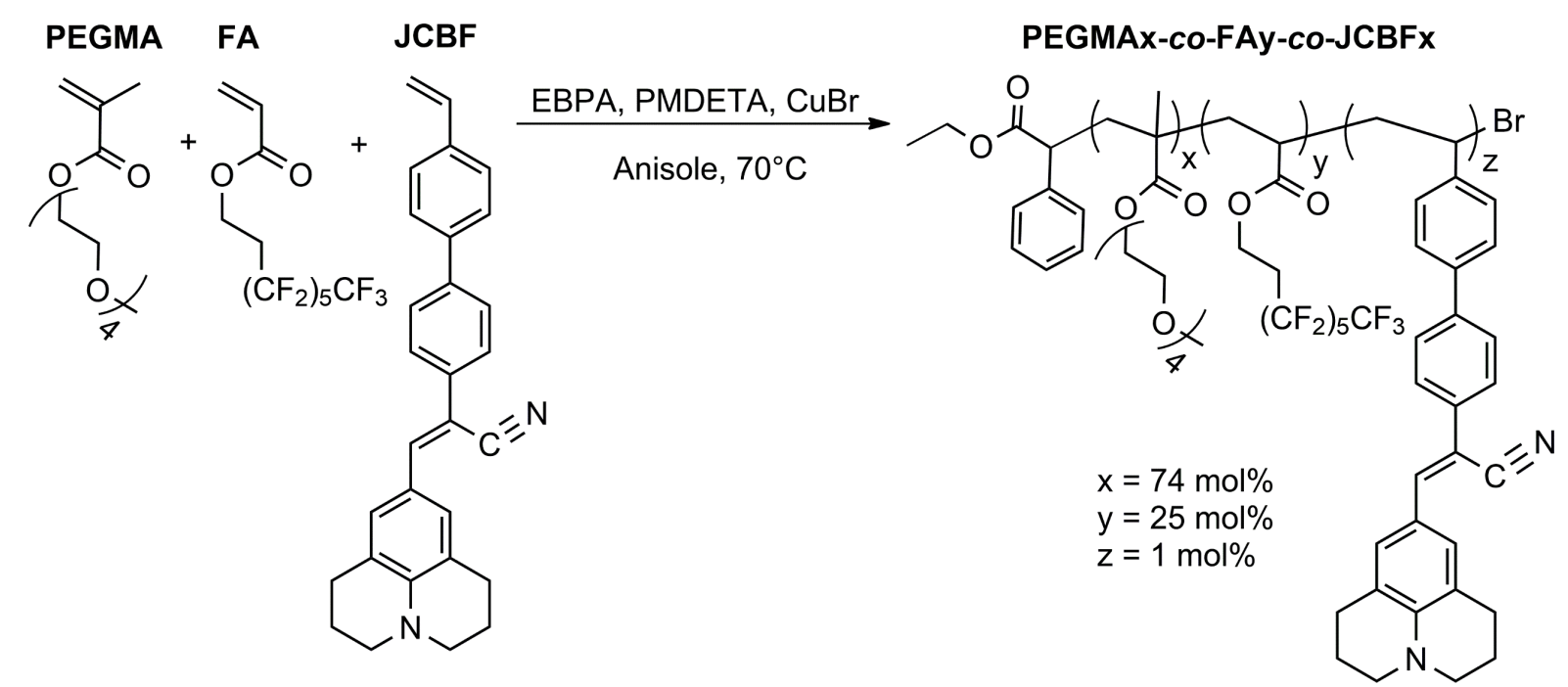

Figure 1. Synthesis of the fluorescent julolidine-labeled amphiphilic terpolymer PEGMA74co-FA25-co-JCBF1 via ATRP.

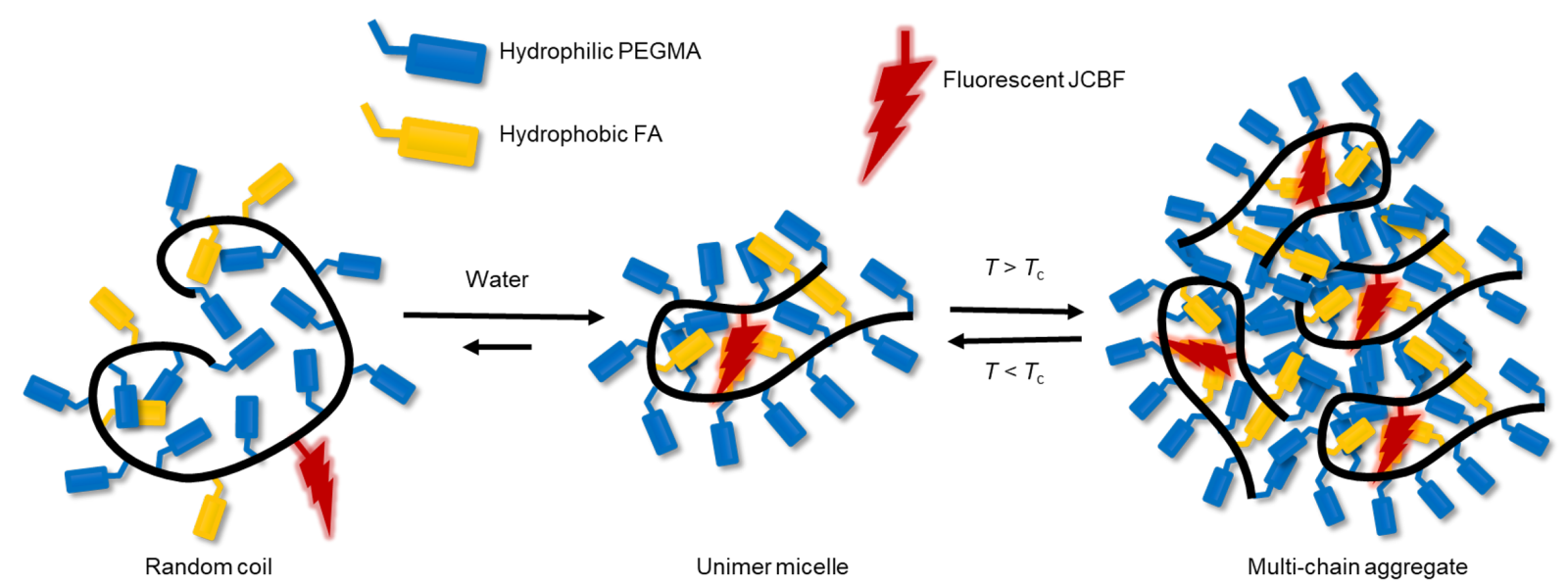

Figure 2. Schematic representation of the unimer micelle in water solution, and multi-chain aggregate formed at $T \geq T_{\mathrm{c}}$.

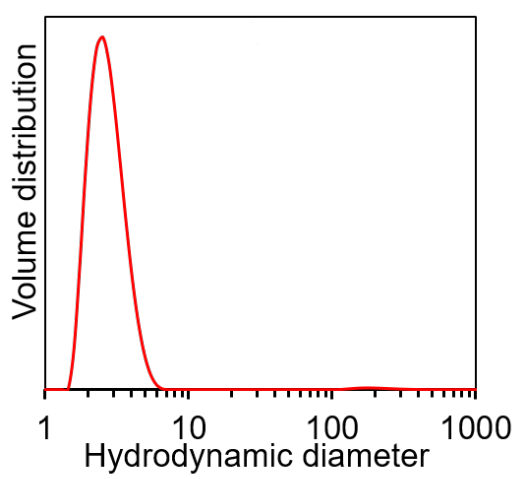

$(\mathrm{nm})$

(a)

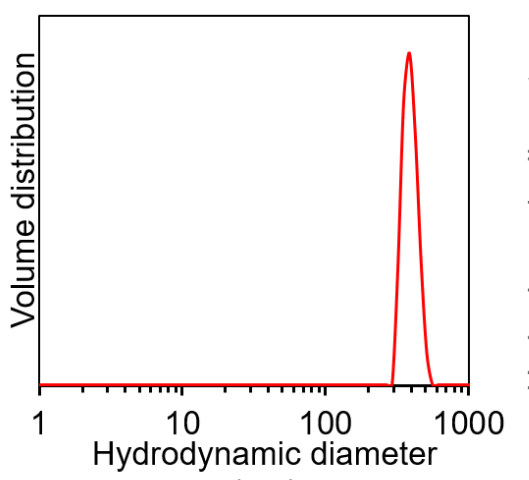

$(\mathrm{nm})$

(b)

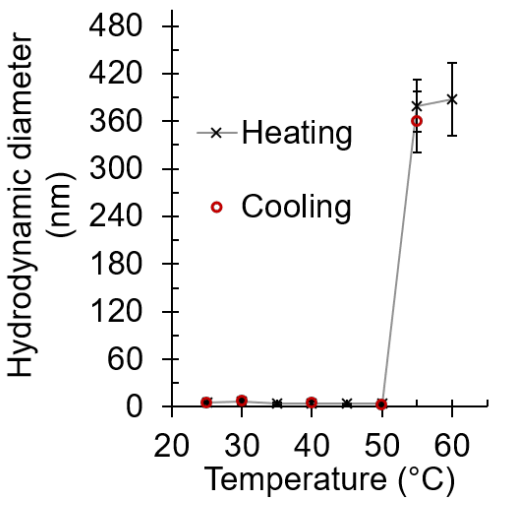

(c)

Figure 3. DLS volume distributions of PEGMA74-co-FA25-co-JCBF1 in water $\left(5 \mathrm{mg} \mathrm{mL}^{-1}\right)$ at $25{ }^{\circ} \mathrm{C}(\mathrm{a}), 60^{\circ} \mathrm{C}(\mathrm{b})$ and variation of the hydrodynamic diameter $\left(D_{\mathrm{h}}\right)$ as a function of temperature $(\mathrm{c})$. 


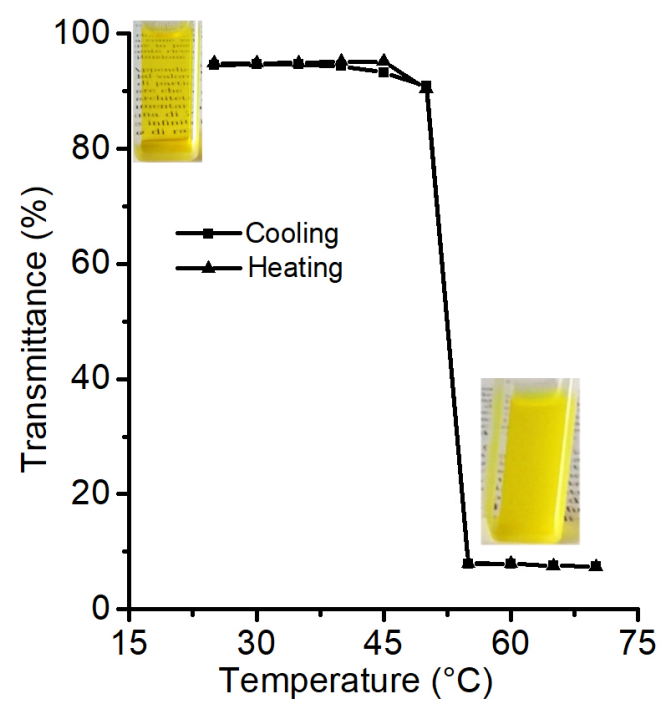

Figure 4. Trend of transmittance $(\lambda=700 \mathrm{~nm})$ of the PEGMA74-co-FA25-co-JCBF1 water solution $\left(2.75 \mathrm{mg} \mathrm{mL}^{-1}\right)$ with temperature (heating-cooling rate and range: $5{ }^{\circ} \mathrm{C} \mathrm{min}^{-1}, 15-$ $75^{\circ} \mathrm{C}$ ). In the insets: pictures of the PEGMA74-co-FA25-co-JCBF1 in water at $\mathrm{T}<T_{\mathrm{c}}$ and $\mathrm{T}$ $>T_{\mathrm{c}}$.

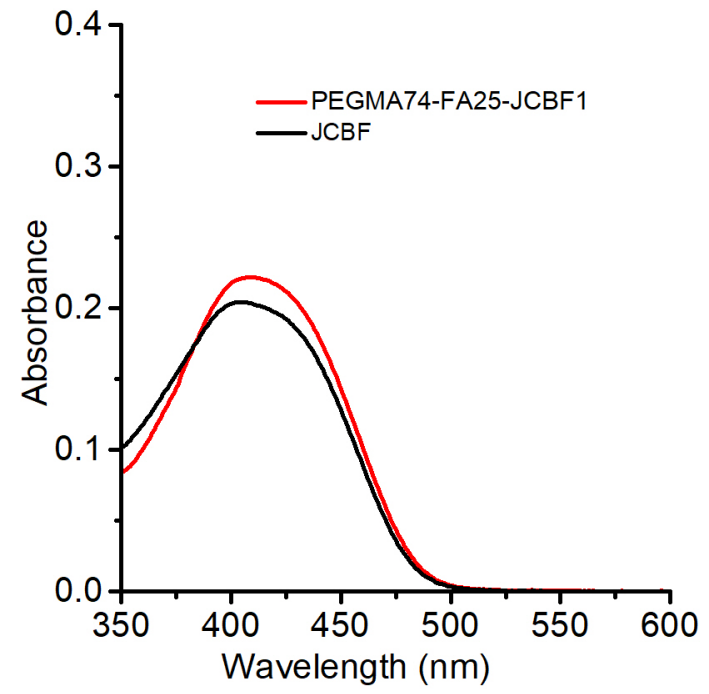

(a)

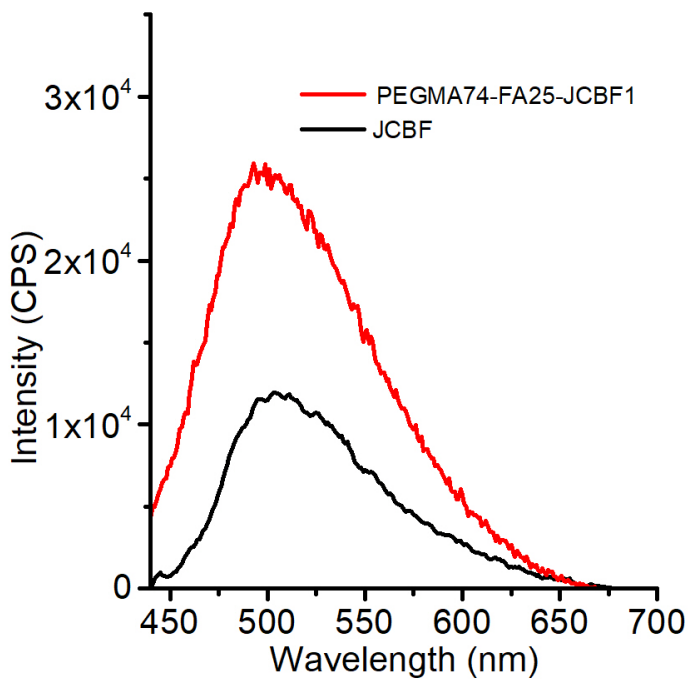

(b)

Figure 5. UV-vis absorption spectra (a) and fluorescence emission $\left(\lambda_{\text {exc }}=405 \mathrm{~nm}\right)$ spectra (b) of PEGMA74-co-FA25-co-JCBF1 $\left(0.36 \mathrm{mg} \mathrm{mL}^{-1}\right)$ and the corresponding JCBF monomer $\left(1 \cdot 10^{-5} \mathrm{M}\right)$ in chloroform solution. 

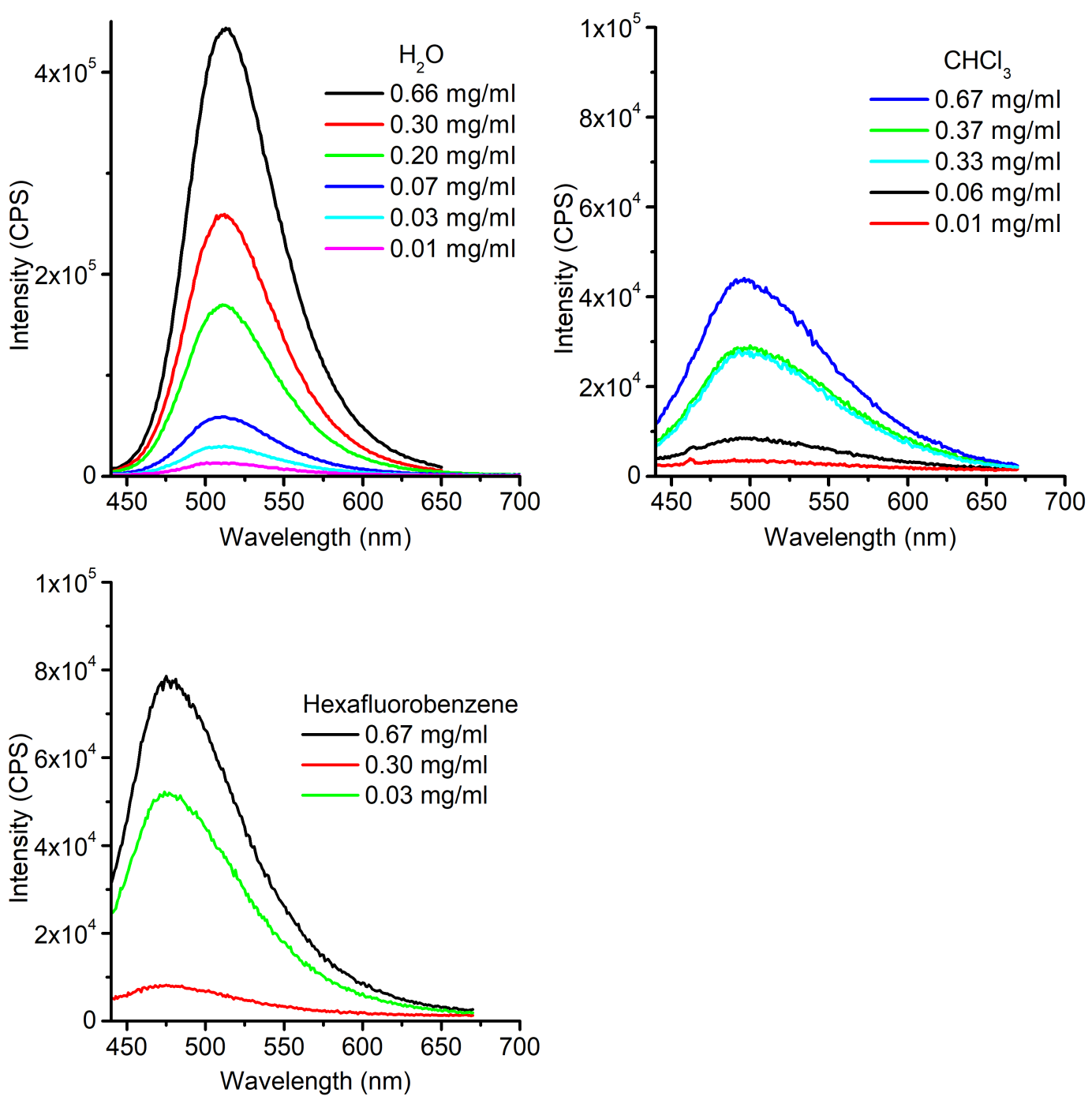

Figure 6. Fluorescence emission spectra $\left(\lambda_{\mathrm{exc}}=405 \mathrm{~nm}\right)$ of PEGMA74-co-FA25-co-JCBF1 in water, chloroform and hexafluorobenzene solutions at different concentrations.

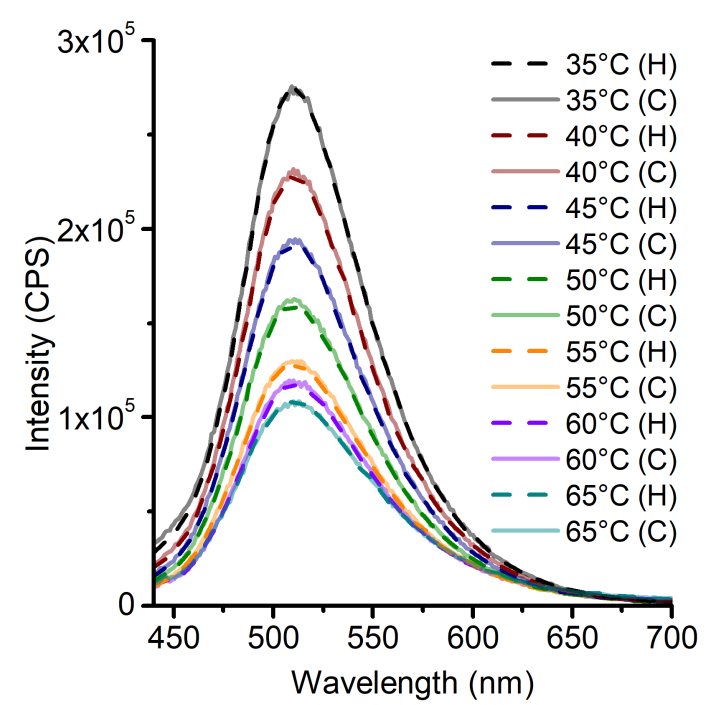

(a)

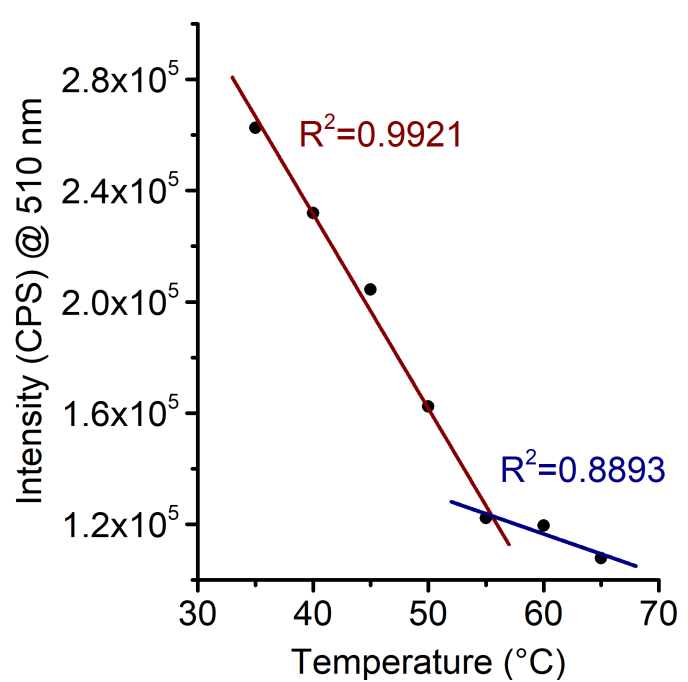

(b)

Figure 7. (a) Fluorescence emission spectra $\left(\lambda_{\mathrm{exc}}=405 \mathrm{~nm}\right)$ of PEGMA74-co-FA25-coJCBF1 in water solution $\left(0.5 \mathrm{mg} \mathrm{mL}^{-1}\right)$ during heating $(\mathrm{H})$ and cooling $(\mathrm{C})$ cycles. (b) Fluorescence intensity maximum plotted as a function of temperature. 


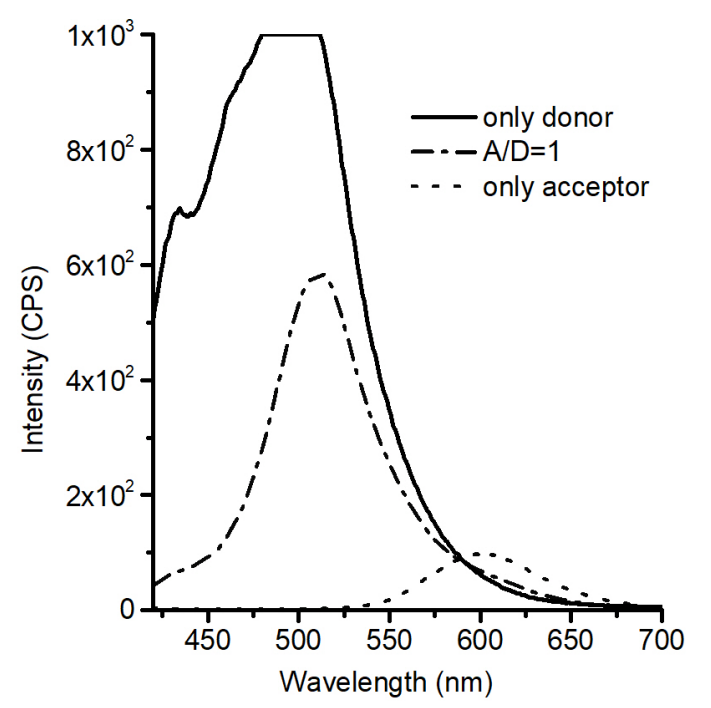

Figure 8. Fluorescence emission spectra $\left(\lambda_{\mathrm{exc}}=405 \mathrm{~nm}\right.$, water solution) of PEGMA74-coFA25-co-JCBF1 (7.99 $10^{-5} \mathrm{M}$ donor (D)), EtBr $\left(7.08 \cdot 10^{-5} \mathrm{M}\right.$ acceptor (A)) and PEGMA74co-FA25-co-JCBF1 $+\operatorname{EtBr}\left(7.99 \cdot 10^{-5} \mathrm{M}\right.$ and $7.08 \cdot 10^{-5} \mathrm{M}$, respectively). 


\section{GRAPHICAL ABSTRACT}

Elisa Guazzelli, Elena Masotti, Tarita Biver, Andrea Pucci, Elisa Martinelli, ${ }^{*}$ Giancarlo Galli

The self-assembly over nano- to submicro- length scales in water of a fluorescent julolidine-labeled amphiphilic random terpolymer

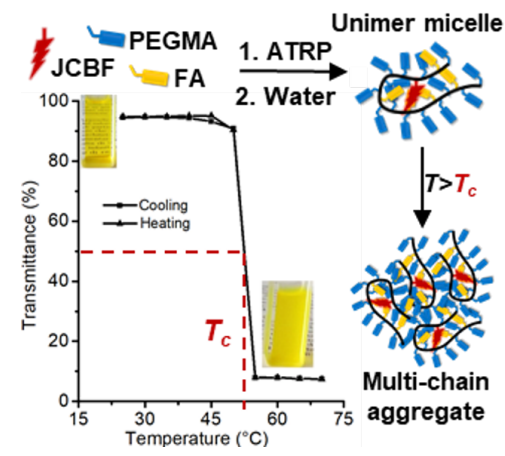
A novel julolidine-labeled amphiphilic terpolymer is synthesized by ATRP in order to study its self-associative behavior by fluorescence spectroscopy in addition to DLS analysis. The terpolymer forms unimer micelles by single-chain folding in water, which collapse into larger multi- chain aggregates at a critical temperature. Such a thermo-responsive behavior is reversible with no hysteresis. 